\title{
El paratext en la narrativa de Carme Riera: títols, dedicatòries i epígrafs
}

\author{
Paratexts in the Narrative of Carme Riera: Titles, Dedications \\ and Epigraphs
}

\section{Mireia FerRando}

(Universitat de València)

mireia.ferrando@uv.es

Recibido: Septiembre de 2016. Aceptado: Noviembre de 2016

Resum: La paratextualitat ocupa un espai destacat en la construcció del sentit de les obres de Carme Riera. No obstant això, no hi ha actualment cap línia d'investigació que l'estudie en la seua transversalitat. A partir de les teoritzacions de Gérard Genette sobre el paratext, exposades a Seuils (1987), aquest article analitza tres de les categories paratextuals més representatives -títols, dedicatòries i epígrafs- presents a l'obra narrativa que Riera ha publicat al llarg de quaranta anys de trajectòria literària (1975-2015). L'enfocament adoptat permet apuntar les pautes funcionals més rellevants del paratext rierià i, de retruc, demostra el notable interès que té l'escriptora mallorquina per obtenir la màxima rendibilitat literària de l'aparell paratextual. En paral-lel, s'observa que el paratext no és sols una via de comprensió d'una obra particular, sinó també de tot l'univers literari, compacte i irreductible alhora, que dissenya Carme Riera.

Paraules clau: Carme Riera, paratext, títols, dedicatòries, epígrafs, narrativa catalana actual

\begin{abstract}
Paratexts play a prominent role in the construction of sense in the works of Carme Riera. However, there is no line of research aimed at studying its transversality. Based on the theoretical work by Gérard Genette on paratext, appeared in Seuils (1987), this article analyses three of the most representative paratextual categories: titles, dedications and epigraphs, all present in the work of Riera throughout her 40 years of literary career (1975-2015). This approach will allow us to emphasize the most relevant functional patterns in Riera's paratext and, at the same time, will show the high interest by the Mallorcan writer to make use of paratexts as a literary tool. The article will ultimately show also that paratexts are not only a way of understanding a particular piece of work but also the whole literary universe designed by Carme Riera, compact and indomitable as it is.
\end{abstract}


Key Words: Carme Riera, paratext, titles, dedications, epigraphs, Catalan contemporary narrative

\section{INTRODUCCIÓ}

És de sobres conegut l'impacte que va provocar la irrupció de Carme Riera en el camp de les lletres catalanes fa poc més de quaranta anys, gràcies a la publicació de Te deix, amor, la mar com a penyora. Des d'aquell 1975 i fins a dia d'avui, la seua producció literària no ha deixat de captivar lectors i ha suscitat un interès científic de primera magnitud, del qual, per inabastable, no podríem ara donar compte. Això sí, ens sembla just reconèixer noms com els de Lluïsa Cotoner, Francesco Ardolino, Carme Gregori o Lluïsa Julià perquè, amb les seues aportacions, moltes de les quals seran comentades al llarg de les pàgines següents, han contribuït a establir una base crítica sòlida a partir de la qual se sustenta la nostra recerca.

Aquest estudi se centra a explorar una part del discurs literari sovint considerada accessòria, com és la paratextualitat, que no ens consta que haja estat abordada fins al moment de la manera com ací la plantegem. La nostra motivació és ben senzilla: en el cas de Carme Riera, la paratextualitat és un espai facultatiu recurrent $\mathrm{i}$, a més a més, rellevant, en tant que forma part del joc literari i participa en la proposta estètica i de sentit present en l'univers diegètic de les obres. Més enllà de referències disperses i fragmentades a diversos paratextos, subordinades sempre a l'anàlisi d'alguna obra concreta, que certament existeixen, ens proposem, doncs, estudiar el paper que ocupa la paratextualitat en el conjunt de la narrativa de Carme Riera i demostrar que constitueix una clau d'accés ben productiva a tot el seu univers literari.

Ara bé, parlar de paratext és referir-se a una categoria molt àmplia i heterogènia, que integra al seu si des del títol de l'obra, les dedicatòries o els prefacis fins a la coberta, les il-lustracions o les ressenyes sobre el llibre. Cal precisar, per tant, que en tot moment ens referim a allò que Gérard Genette (1987: 14) ha anomenat «paratexte auctorial», és a dir, a tots aquells discursos paratextuals que són responsabilitat directa de l'autor ${ }^{1}$. Dins del paratext auctorial, atendrem el peritext, és a dir, els discursos situats en la materialitat del llibre, i exclourem, d'entrada, l'epitext (entrevistes, diaris personals, correspondència, etc.), ja que això requereix una investigació molt més exhaustiva que excediria l'abast i l'extensió del present treball. L'anàlisi dels títols, les dedicatòries i els epígrafs serà, doncs, l'eix vertebrador d'aquest article, que ens aprofitarà per a acostar-nos des d'aquest cantó a la literatura de Carme Riera² .

${ }^{1}$ D'ara endavant, ens hi referirem amb el terme «paratext auctorial», fidel a l'opció original genettiana.

${ }^{2}$ En un altre article, en premsa per a Estudios hispánicos, «Els prefacis ficcionals en la narrativa de Carme Riera», ens hem ocupat de l'estudi dels prefacis que, en ser l'element més substanciós del paratext auctorial, demanava una atenció específica. Tanmateix, com és natural, les conclusions del susdit estudi vénen a coincidir amb les que ací oferim. 
Per tal d'assolir l'objectiu adés esmentat treballarem amb totes les obres de ficció en català i les dues elaborades en clau autobiogràfica que l'escriptora mallorquina ha publicat al llarg de quaranta anys de trajectòria literària: Te deix, amor, la mar com a penyora (1975), Jo pos per testimoni les gavines (1977), Una primavera per a Domenico Guarini (1980), Epitelis tendríssims (1981), Qüestió d'amor propi (1987), Joc de miralls (1989), Contra l'amor en companyia $i$ altres relats (1991), Dins el darrer blau (1994), Temps d'una espera (1998), Cap al cel obert (2000), La meitat de l'ànima (2004), L'estiu de l'anglès (2006), Amb ulls americans (2009), Natura quasi morta (2011), Temps d'innocència (2013) i La veu de la sirena (2015).

\section{ELS TÍTOLS}

D'acord amb Genette (1987: 73), el títol és un «objet de circulation -ou, si l'on préfère, un sujet de conversation», a diferència del text, que és «objet de lecture». El destinatari d'aquest paratext, per tant, no és solament el lector, sinó també el públic general, que coneix el llibre i en pot parlar tot i no haver-lo llegit. Aquest fet ens permet comprendre per què estem al davant d'una instància ben significativa a l'hora de crear o trencar expectatives prèvies a la lectura i configurar la recepció pretesa de l'obra.

Segons la proposta genettiana (1987: 54-97), un títol literari pot exercir quatre funcions: la funció de designació o identificació, la funció descriptiva, la funció connotativa i la funció de seducció. La primera identifica i particularitza el text atorgant-li un nom propi, de manera que esdevé l'única funció obligatòria, per la imperiosa necessitat d'adoptar-ne un. Com ha fet notar Genette mateix, la funció descriptiva és gairebé ineludible, ja que el títol deixa entreveure, ni que siga implícitament, claus descriptives i interpretatives del text. Aquesta segona funció abraça, al seu torn, tres tipus de títols: a) els títols temàtics -literals si fan referència a elements centrals del món diegètic, metonímics si aborden aspectes secundaris o marginals, metafòrics quan arrosseguen una dimensió simbòlica, i antifràstics o irònics si contradiuen el text a què donen nom-; b) els títols remàtics -genèrics o paragenèrics si designen el gènere, formals quan mencionen aspectes formals («pàgines», «manuscrits», etc.) o resultants de la rematització d'un títol temàtic previ; i c) els títols mixts, que combinen l'aspecte temàtic i el remàtic. La funció connotativa es vincula amb el valor connotatiu, intencionat o no, d'aquest paratext. Pel que fa a la funció de seducció, lligada al poder d'atracció del públic real i potencial de l'obra, Genette es mostra escèptic per la dificultat que suposa analitzar-la objectivament. Existeix la possibilitat, perversa però real, que l'atractiu del títol acabe convertint-se en un inconvenient per a la recepció del text.

No cal dir que acceptem per endavant la naturalesa convencional i matisable de tota classificació. Tanmateix, hem considerat avantatjós aquest marc teòric per a descriure de manera operativa l'ús dels títols en la narrativa de Carme Riera. Certament, ens ha permès detectar una inqüestionable preferència per l'element temàtic, ja que quinze dels setze títols rierians el tenen. Només un, Contra l'amor en companyia $i$ altres relats, combina una designació temàtica i 
una genèrica i, per tant, el considerem mixt. Aquesta conclusió avançada ara ens permet justificar l'atenció preferent que atorgarem als títols temàtics del nostre corpus. Tot i això, no deixarem de banda l'anàlisi d'aquest paratext en relació a les línies dominants en la producció literària de l'escriptora.

Dels quinze títols temàtics, n'hem detectat, per un costat, sis clarament literals: Qüestió d'amor propi, Temps d'una espera, L'estiu de l'anglès, Amb ulls americans, Temps d'innocència i La veu de la sirena. Cal que ens aturem momentàniament per a advertir que considerar aquests títols dins de la categoria dels literals, és a dir, dels que designen de manera directa el tema o algun element rellevant de l'obra, no implica en cap cas rebutjar una possible dimensió metafòrica o irònica afegida. De fet, un cas evident el trobem a Amb ulls americans. Epps (2011: 122) ha fet notar el joc de paraules que s'amaga darrere d'aquest títol, atès que equival en fonètica mallorquina a dir «embulls americans», entenent la paraula embulls d'una manera polisèmica: d'una banda, referida a la confusió i el desconcert amb què el protagonista nord-americà veu la realitat catalana $i$, de l'altra, vinculada al ric i complex teixit intertextual amb què compta l'obra. De fet, ha estat la mateixa Riera qui ha assenyalat el caràcter irònic i caricaturesc del títol que, com qualsevol història, pot contenir diversos sentits «y a mí me ha gustado siempre servirme de ellos, sobre todo en los títulos» (Durán 2009). La novel-la presenta també un subtítol, «Segons 1'experiència barcelonina de George Mac Gregor», que revela la identitat del protagonista i el filtre a través del qual es narrarà la història. Aquest avançament interpretatiu no apareix, però, a la coberta del llibre sinó a l'interior, a la pàgina de portada.

En Qüestió d'amor propi, la història gira entorn d'una venjança amorosa motivada, precisament, per un orgull propi ferit. Temps d'una espera i Temps d'innocència són dues obres -la primera, en forma de dietari, i la segona, de memòries- lligades a dos «temps» de la vida de l'escriptora: el de l'espera motivada per l'embaràs i el de la innocència associada a la infantesa. En el primer cas, sabem que el títol del llibre ha sofert una lleugera modificació respecte al que portaven els seus manuscrits íntims, Quaderns d'espera, tal com Riera revela al pròleg (1988b: 11).

Per un altre costat, hem detectat que en set títols predomina clarament l'element metafòric o simbòlic: Te deix, amor, la mar com a penyora, Jo pos per testimoni les gavines, Joc de miralls, Dins el darrer blau, Cap al cel obert, La meitat de l'ànima i Natura quasi morta.

En una entrevista per a la Televisió de Catalunya (2014), la mateixa Riera confessava la dificultat que li suposa de vegades titular les seues obres: «Els meus títols normalment surten de l'última ratlla [...] Em costa molt titular i, aleshores, crec que les darreres paraules [...] d'una història són importants i les aprofito pel títol». D'aquestes declaracions, no gens gratuïtes, es desprèn la rellevància simbòlica que l'autora atorga a les darreres paraules de les històries, que en diverses ocasions li han servit per a donar nom al llibre. Aquest procediment és emprat en els seus dos primers reculls de relats, Te deix, amor, la mar com a penyora i Jo pos per testimoni les gavines, i en les novel-les històriques, Dins el darrer blau i Cap al cel obert. Els títols de la primera parella d'obres, 
en què la mar i les gavines actuen com a símbols d'unes promeses d'amor, corresponen a la frase final dels contes que encapçalen i donen nom als respectius reculls ${ }^{3}$. Com han fet notar Ardolino (2000: 1, 2006: 28) i Julià (2009: 25), es tracta de dos decasílllabs femenins que estableixen un joc polifònic, ja que la primera carta de Jo pos per testimoni les gavines és, en realitat, una resposta explícita al conte-carta que obre el llibre anterior. Pel que fa al segon cas, amb Dins el darrer blau l'autora inicia una línia de producció dedicada als xuetes mallorquins que clou amb Cap al cel obert. Els títols de les dues obres coincideixen també amb les darreres paraules dels desenllaços respectius que, curiosament, també presenten similituds:

Anar-se'n tot d'una, lluny, ben lluny, que la sagetia llevi l'àncora de seguida i es perdi falaguera, de pressa, enfora, molt enfora, dins el darrer blau. (Riera 2013: 442)

[...] i ambdós s'enlairarien altre cop de pressa, amunt, fins a perdre's, enfora, cap al cel obert. (Riera 2014a: 346)

Igual com abans, és inevitable posar en relació ambdós títols. Tot i que el paral-lelisme no és explícit com en el cas anterior, els sintagmes comparteixen també el còmput sil-làbic, a més d'un doble sentit literal i metafòric (Cotoner 1996, Valls 2000: 306). Així, les referències espacials al marc escènic exterior adquireixen categoria simbòlica en el moment que remeten als anhels i les limitacions interiors dels personatges.

A més a més, hem observat que l'autora no només fa servir les últimes ratlles de la història per a titular aquestes quatre obres, sinó que també empra sintagmes significatius disseminats al llarg de les històries. Ocorre, per exemple, en La meitat de l'ànima, en què hem detectat la presència del títol (o del que serà el títol) en el fragment següent:

Per a mi la memòria és imprescindible, sense la memòria som morts. La memòria és l'ànima de les persones $i$ tal vegada és per això que jo seguesc cercant la meitat de la meva ànima. (Riera 2004: 168)

Si tenim en compte que la novel.la tracta d'una recerca identitària (Corrons + Frayssinhes 2010: 115-200), el títol pot entendre's com una al-lusió metafòrica a la memòria, sovint incompleta i fràgil, però clau de l'existència humana. La protagonista, sumida en una crisi existencial, necessita reconstruir el passat perquè la seua realitat recobre el sentit, $i$ ho ha de fer mitjançant un procés de recerca que ha d'anar més enllà de la pròpia història.

Un altre exemple de presència del títol al text és Natura quasi morta (2015b: 30, 215). Aquest cas s'inspira en el contrapunt simbòlic entre vida i

\footnotetext{
${ }^{3}$ El títol Jo pos per testimoni les gavines en realitat ha patit una mínima modificació respecte a la frase final de la carta, que és «Les he vistes, ho jur i en pos per testimoni les gavines», encara que segons Ardolino (2000), és consequiència de la facultat que qui escriu aquesta carta atorga a la destinatària, l'autora de Te deix, perquè faça els canvis en la història que considere oportuns.
} 
mort present a les natures mortes plàstiques del pintor Georg Flegel, que és transportat a la novel-la. La partícula «quasi» crea l'ambigüitat idònia per a inquietar el lector i genera la intriga pròpia del gènere policíac. A Dins el darrer blau, trobem també dins de la història una menció literal a aquest sintagma (2013: 195) i diverses al·lusions indirectes i contínues a la mar, així com també passa a Joc de miralls pel que fa als espills. Aquest procediment, però, no és només vàlid per als títols metafòrics, ja que també a Qüestió d'amor propi (1987b: 68) es fa servir.

A més de les relacions temàtiques que estableixen tots aquests títols rierians amb els textos corresponents, cal prendre en consideració el fet que alguns d'ells també revelen constants de la producció literària de l'escriptora. El cas paradigmàtic el constitueix, precisament, Joc de miralls, que apunta d'una banda al tema del doble i, de l'altra, a la reflexió sobre la condició metaficcional de la literatura. Com ha advertit Gregori (2013: 14), «no és per casualitat que aquest títol ha estat emprat de forma reiterada per la crítica per a denominar el conjunt de l'obra rieriana». I, en efecte, la literatura de l'autora sembla moure's en un joc permanent de miralls, en els quals es reflecteixen la construcció del jo (o la identitat) en relació a l'altre (o l'alteritat) i l'autoreferencialitat de la literatura.

No podem deixar d'esmentar un altre dels elements nuclears de l'obra rieriana, com és la ironia, que queda reflectida al títol Epitelis tendríssims. El contrast que s'estableix entre el seu lirisme i el contingut del text -contes eròtics en clau lúdica- ens porta a classificar-lo com a títol irònic. En aquest punt, a més a més, cal advertir que la ironia també apareix a diversos intertítols, és a dir, als títols que es troben a l'interior de l'obra i encapçalen contes, capítols, seccions, etc. (Genette 1987: 271-292), tot i que no podem abordar la seua anàlisi específica perquè ens portaria a ampliar el corpus d'estudi d'una manera ací inassolible. Tanmateix, a tall d'exemple, creiem escaient fer menció al títol del relat «Això no és un conte» (Riera 1991: 163-169), que mostra d'una manera nítida la dimensió antifràstica i irònica a què es referia Genette. De nou, el contrast lúdic que s'estableix entre el títol, que desmenteix el caràcter ficcional de l'obra, i el seu text, que al contrari del que es podria esperar sí que és un conte, obliga a replantejar-se la relació entre realitat i ficció. En realitat, estem al davant d'un mecanisme emprat deliberadament per a subratllar-ne l'estatus ficcional, mitjançant el qual l'autora «enfoca l'atenció del lector sobre el pacte literari, sobre la condició d'artefacte del text i sobre la naturalesa de la ficció.» (Gregori 2011: 55).

El joc entre literatura i realitat no és, tanmateix, l'única constant de la producció de Riera marcada als títols. El gust per l'art, per exemple, és una font d'argument literari recurrent en la seua obra i ompli els textos de referències pictòriques constants (Ramon 2013). A més del títol Natura quasi morta, ja esmentat, cal destacar el de la seua primera novel-la, Una primavera per a Domenico Guarini, que exemplifica l'ambigüitat que, tal com adverteix Genette (1987: 80), enclouen alguns títols. En aquest cas, es podria interpretar que parteix d'una literalitat si pensem en el cèlebre quadre del pintor renaixentista italià Sandro Botticelli, contra el qual atempta Domenico Guarini. Ara bé, el títol adquireix connotacions metafòriques en significar l'esclat maduratiu de la protagonista, ja que l'art, com 
la literatura, possibilita el viatge cap a l'(auto)coneixement. En aquest sentit, caldria considerar-lo com a simbòlic. A més a més, si relacionem, tal com proposa Ramon (2013: 67), «la complexitat iconogràfica del quadre» amb «l'enfocament polièdric de cada personatge i la multiplicitat de línies argumentals», la dimensió simbòlica del títol esdevé incontestable. Encara, en relació amb el títol d'aquesta novel-la, hem de ressenyar l'aportació de Machein (2009: 167), qui ha vist en el nom de l'obra un comentari irònic sobre el fetitxisme de Guarini i les conseqüències fatals que li comportarà, una afirmació que no trobem suficientment argumentada com per a subscriure-la.

Finalment, a mode de comentari anecdòtic, ens hem fixat en la manera com Riera manifesta als títols la seua indissociable mallorquinitat, entesa com a punt de vista particular a partir del qual es mira el món. Aquest caràcter mallorquí que tant reivindica i que impregna tota la seua obra, tant en l'àmbit temàtic com en el lingüístic, només es manifesta als títols dels dos primers reculls de relats. Tan sols Te deix, amor, la mar com a penyora i Jo pos per testimoni les gavines evidencien explícitament aquesta procedència mallorquina a través de les formes verbals que, curiosament, desapareixen de l'estructura lingüística de la resta de títols, al mateix temps que es difumina el lirisme de la seua producció primerenca. No serà fins a Amb ulls americans, publicat trenta quatre anys després, que, si fem cas a la hipòtesi defensada per Epps (2011), l'autora recupera l'accent mallorquí al títol, això sí, d'una manera lúdica i oculta. Les causes, però, escapen el nostre objecte d'estudi.

Tenint en compte tot allò exposat, no queda dubte que els títols juguen un paper fonamental dins la proposta literària de Carme Riera. Al costat de la pura descripció del contingut, programen la lectura i en proporcionen claus interpretatives. Això sí, no sempre ho fan d'una manera directa, literal, ja que hem vist com la tendència a l'element metafòric o simbòlic és major. A més a més, el seu valor connotatiu esdevé innegable, atès que, aliens a la neutralitat, aporten sempre una càrrega de sentit que, moltes vegades, només es possible desxifrar en finalitzar la lectura del text. Un altre aspecte que convé destacar és que els títols del nostre corpus no han patit modificacions respecte de l'edició original. Alguns, fins i tot, han esdevingut no només objectes de circulació que han possibilitat l'acostament al llibre, sinó referents culturals col-lectius resistents al pas del temps. Un símptoma que revela, doncs, l'atenció primordial i meditada que l'autora concedeix al títol ja des d'un primer moment.

\section{LES DEDICATÒRIES}

Una dedicatòria d'obra és un enunciat performatiu que Genette (1987: 110-133) associa a un homenatge públic. A grans trets, l'autor de l'obra (o dedicador) fa saber que lliura simbòlicament el seu text al destinatari (o dedicatari), amb qui comparteix algun tipus de vincle afectiu (com ara, familiar o amistós) o manifesta una relació intel-lectual o professional. Del primer, Genette en diu dedicatari privat, mentre que al segon s'hi refereix com a dedicatari públic, sense que això implique una divisió excloent. No cal ni dir que l'autor de l'obra també pot emprar en aquest espai paratextual un registre lúdic, per exemple, recorrent al 
joc metalèptic en què dedicador o dedicatari pertanyen a l'univers diegètic. La casuística és molt àmplia i el recompte de possibilitats, per tant, inassolible. El lector és, però, en tots els casos, el testimoni latent d'aquesta relació entre dedicador i dedicatari. Amb el benentès que es tracta d'un paratext facultatiu, Genette entén que la dedicatòria seria també una marca d'ostentació, per mitjà de la qual l'autor busca exhibir algun tipus de relació amb el dedicatari a fi de construir una determinada imatge de si mateix.

Centrant-nos, doncs, en la narrativa de Carme Riera, hem observat que la inclusió de dedicatòries d'obra és un exercici sistemàtic. Ben mirat, es tracta de l'únic paratext, naturalment al costat del títol, que apareix d'una manera constant en la totalitat del nostre corpus d'anàlisi. Una presència recurrent que esdevé, fins i tot, abusiva en les produccions que conformen la seua primera etapa literària, en què els dedicataris són múltiples i les dedicatòries no sols encapçalen el llibre, sinó que també se situen al final o a l'inici d'alguns relats. Tot i que es tendeix a atorgar-li una importància menor que a la resta d'elements paratextuals pel fet de semblar, en principi, un missatge més autònom respecte al text, o poc transcendent, la dedicatòria ocupa en realitat un espai privilegiat des d'on condicionar la lectura o projectar una determinada imatge de l'obra o de l'autor i, per aquest motiu, cal prendre-la en consideració.

D'entrada, endinsar-se en l'anàlisi d'aquest paratext requereix atorgar una atenció particular a la primera etapa productiva de Riera, conformada pels reculls Te deix, amor, la mar com a penyora i Jo pos per testimoni les gavines i per la novel-la Una primavera per a Domenico Guarini. Aquestes tres obres proven que, des de bon començament, l'escriptora considera la dedicatòria un espai paratextual més des d'on projectar unes determinades característiques del seu univers literari. Un tret sens dubte definitori dels primers reculls és la presència de dedicatòries de caràcter públic que avancen alguns dels centres d'interès temàtic de les narracions. La dedicatòria final del primer llibre palesa una preocupació per aquells que no encaixen en la societat:

A Eva, a la dona.

Als que no hi són tots...

Als que es passegen pel braç de la anormalitat.

Als difícils.

Als isolats.

Als pervertits.

A aquells a qui contorba la bellesa...

Però també a tots els altres.

Com observa Guillem Frontera al pròleg (1981a: 12), els personatges que pul-lulen pels contes $-i$, en certa manera, podríem dir que les personalitats que interessen Riera- "no han sabut, no han pogut o no han volgut ser assimilats per l'engranatge de la "normalitat" quotidiana». I, en aquest punt, no passa inadvertida la menció inicial «A Eva, a la dona», que anticipa no sols una pista 
temàtica, sinó una constant de la seua producció com és l'atenció privilegiada a la condició femenina. Si tenim present que Nichols (2011: 15-32) ha trobat punts de referència entre la història de Te deix, amor, la mar com a penyora i el llibre del Gènesi, és evident que cal considerar aquesta dedicatòria com un homenatge a l'Eva bíblica, primera dona i primera transgressora de l'ordre establert segons el relat religiós, i per extensió, a totes les dones. La dedicatòria final de Jo pos per testimoni les gavines té en compte aquest precedent, en insistir en el reconeixement a la dona, però a més hi afegeix la referència a una dedicatària concreta: «A Eva F., a la dona, segona vegada, ara que han passat més anys. I també als qui amb ella lluitaren i lluiten». En una entrevista amb Nichols (1989: 222), Riera reconeix que «Eva F.» és Eva Forest i que aquesta dedicatòria no és consequiència d'un lligam amistós, sinó que s'ha d'entendre com un homenatge a tot un símbol de l'activisme feminista i antifranquista d'aquells moments (1989: 222). Precisament aquesta al-lusió simbòlica s'adequa a la perfecció a una de les línies temàtiques de Jo pos per testimoni les gavines, que incideix d'una manera més explícita en la crítica de la societat i en la denúncia clara del feixisme franquista, fruit segurament d'haver estat escrit en un any, el 1977, en què la possibilitat de justícia i reparació s'albirava com a real. Per exemple, el conte «D'un temps, d'uns ulls» porta per dedicatòria «A Marina Rossell, per la cançó del lladre, i en homenatge i memòria als assassinats per la dictadura feixista» (Riera 1998a: 21) i el conte «Helena, Helena» està dedicat «En homenatge i memòria de J. F. M. i de tots els exiliats del meu país» (Riera 1998a: 27).

Si bé s'observa com l'al-lusió «a la dona, segona vegada» d'aquest segon recull manifesta una voluntat continuadora evident amb el primer, que ja havia estat dedicat «a la dona», no podem deixar d'esmentar una altra marca, encara més notable, que connecta els dos llibres des de l'espai de la dedicatòria. Te deix, amor, la mar com a penyora i Jo pos per testimoni les gavines comparteixen una dedicatòria inicial idèntica: «A Francesc, a qui aquest llibre pertany quasi tant com a mi». El paper estratègic d'aquest missatge esdevé innegable, atès que funciona com un mecanisme paratextual que, juntament amb els títols, reforça la vinculació entre ambdues obres, alhora que insisteix en la importància d'aquest dedicatari en la vida de l'autora.

L'etapa literària primerenca es tanca amb Una primavera per a Domenico Guarini. A més del reconeixement a Luisa Cotoner, Riera desvela mitjançant la dedicatòria que el dedicatari Francesc de les obres anteriors és el seu marit, per qui sent una estima sincera i un respecte profund. Amb el missatge, d'extensió considerable, subratlla una imatge de dona enamorada que perpetuarà durant tota la seua trajectòria. Machein (2009: 167) suggereix l'existència d'un parallelisme entre la declaració d'amor de Riera i l'amor idealista de Guarini per Laura, interpretació que trobem discutible, ja que a la novel-la hi ha precisament el qüestionament de l'amor idealitzat, que a la protagonista no li serveix com a model de feminitat o norma de vida. En canvi, la dedicatòria a Francesc no és en absolut ideal, sinó real. A més a més, la versió castellana redueix d'una manera considerable l'extensió de la declaració amorosa per un concís «A Francisco Llinás, siempre», motiu que ens indueix a pensar que la dedicatòria de la versió catalana no pot ser una pista temàtica com afirma la investigadora ale- 
manya. Gràcies a l'entrevista amb Nichols (1989: 220) sabem que l'abreujament dràstic del missatge responia a un consell de Carmen Balcells, que «me aconsejó que esa dedicatoria era completamente impúdica y que la quitara, que no se podía poner una dedicatoria así. [...] Balcells decía que para el público castellano no tenía sentido y yo obedecí». Per contra, resulta significatiu que en les successives reedicions en català la dedicatòria originària no haja sofert cap modificació.

L'allunyament del lirisme que comporta el tancament d'aquest primer període literari es percep també en les dedicatòries. Per exemple, l'afany de capgirar els codis socials tradicionals, que quedava dibuixat explícitament en dedicatòries de l'etapa primerenca, desapareix d'aquest espai paratextual. Ara, els missatges s'adrecen sovint només a dedicataris personalitzats, amb qui l'autora manté algun tipus de vincle afectiu o professional o, si ho diem a la manera genettiana, algun tipus de relació de caràcter públic o privat.

Per un costat, els dedicataris privats, que ja apareixen en les primeres obres, relacionats sobretot amb Riera per vincles familiars o amistosos, dominen gairebé en exclusiva en tota la producció literària posterior. Una revisió panoràmica d'aquest paratext permet constatar que la dedicatòria a l'entorn familiar és la més reiterada i fonamental: al seu marit, a més de les tres obres pertanyents a la primera etapa productiva ja esmentades, dedica, explícitament, Qüestió d'amor propi. Els seus fills Ferran i Maria són els dedicataris de Temps d'una espera i, per separat, Ferran ho és de Te deix, amor, la mar com a penyora i del conte «Elegia per a unes mans» (Riera 1998a: 39-43), i Maria, del volum Contra l'amor en companyia i altres relats. Les dues nétes són les dedicatàries de dues de les seues darreres obres, les memòries d'infantesa que porten per títol Temps d'innocència i La veu de la sirena, una versió transgressora de La Sireneta d'Andersen. Fins i tot, la gossa de la família és la dedicatària, «in memoriam», de la novel-la negra Natura quasi morta. Els seus pares són els dedicataris del conte «Quasi a la manera de fulletons» (Riera 1998a: 45-53) i, per separat, el pare ho és de Dins el darrer blau i la mare de La meitat de l'ànima. El quadre familiar es completa amb la menció de l'àvia Caterina en la dedicatòria de Cap al cel obert.

Per un altre costat, cal assenyalar l'existència d'un bloc minoritari, però significatiu, de dedicataris de caràcter públic amb nom i cognom, amb els quals Riera manté un lligam professional que no exclou la relació personal d'amistat. En general, es tracta de persones que l'han aconsellada o l'han ajudada durant el procés de redacció o de correcció de les obres. És el cas de Luisa Cotoner, dedicatària d'Una primavera per a Domenico Guarini i de Joc de miralls, i d'Isidor Cònsul, «editor i amic», dedicatari d'Amb ulls americans. La dedicatària de Contra l'amor en companyia i altres relats és Teresa Centelles, mentre que L'estiu de l'anglès està dedicat a la professora i traductora Martha Tennent i a la seua agent literària, «A la doctora Carmen Balcells en l'any de l'Horroris», ja que Riera va apadrinar la seua investidura com a doctora honoris causa uns mesos abans de la publicació del llibre.

Amb tot, comptem amb una descripció general que ens avala ara per a tractar tres dels aspectes del corpus de dedicatòries que considerem necessari d'abordar amb més deteniment. En el primer cas, centrem l'atenció en les dues 
novel-les que conformen el cicle sobre els xuetes mallorquins, Dins el darrer blau i Cap al cel obert, ja que les dedicatòries, al pare i a l'àvia respectivament, constitueixen un homenatge a les persones que en van inspirar la gestació i, si anem una mica més enllà, un reconeixement a les dues figures que van motivar la vocació lectora i literària en Riera. L'escriptora explica a Temps d'innocència, al capítol «Xuetona» (2014b: 60-63), que escoltar la paraula despectiva «xuetona», desconeguda per a ella, al pati de l'escola, li va generar una inquietud que ni el pare ni l'àvia no li resoldrien fins passats uns quants anys, quan, segons confessa, l'àvia Caterina li ho va voler explicar:

Em contà les injustícies i humiliacions que havien patit una part dels jueus conversos mallorquins [...]. Jo vaig apuntar tot el que em digué a la primera pàgina de la memòria, amb lletres majúscules i tinta inesborrable. D'allà sortí molt de temps després Dins el darrer blau. (2014b: 63)

Així, en paraules de Bartrina, referides a Cap al cel obert, però aplicables també a Dins el darrer blau, «la remembrança d'un fet històric esdevé el pretext de la novel-la, en concret, i de tota la seva poètica narrativa» (2011: 59). Aquest record gravat en la memòria és, doncs, el pretext que activa en Riera la decisió d'iniciar-se en el gènere històric.

De la mateixa manera que indagar en el passat històric esdevé un exercici per a explicar el temps present, dedicar les novel-les històriques al pare i a l'àvia constitueix també un homenatge als seus orígens lectors i literaris. D'una banda, com relata a les seues memòries d'infantesa, «mon pare m'inoculà el virus de la lectura i alhora me la va prohibir» (2014b: 92). Que ell li llegira la «Sonatina» de Rubén Darío va despertar en ella una curiositat per la lectura que no deixaria ja de créixer, tot i que el pare mateix, en veure que s'havia convertit en lectora compulsiva, va arribar a tancar-li la biblioteca de casa amb pany i clau, fet que no va fer sinó estimular el desig de llegir. Si atenem a aquesta experiència autobiogràfica, la dedicatòria «A mon pare» de Dins el darrer blau pot ser llegida, per tant, com un agraïment a qui va originar en ella la passió lectora ${ }^{4}$.

D'altra banda, l'origen de la condició d'escriptora és atribuïda a la seua àvia Caterina, a qui dedica Cap al cel obert: «A la clara memòria de la meva àvia Caterina, i a les seves històries que no vaig tenir més remei que continuar», ja que com la mateixa autora confessa, «no hauria escrit Cap al cel obert si la meva àvia no m'hagués explicat tota una sèrie d'històries» (Pons + Sureda 2004: 221). Tanmateix, l'àvia no és tan sols la dedicatària de la novel·la, sinó una figura que Riera, amb major insistència que en el cas del seu pare, ha explotat de manera recurrent $\mathrm{i}$ ha acabat convertint en gairebé un tòpic de la seua literatura. L'autora predica aquest fonament de la seua producció literària en

${ }^{4}$ En diverses ocasions, Riera fa al-lusió a aquest episodi vital quan és preguntada sobre com fomentaria la lectura. No sense un cert toc d'ironia, sol afirmar, com reprodueix també a Temps d'innocència, que prohibir-la augmentaria el nombre de lectors: «Al llarg de la meva vida m'han preguntat moltes vegades què faria jo per tal que la gent s'aficionés a llegir i sempre he contestat el mateix: prohibir la lectura. Amb mi, al manco, va funcionar.» (2014b: 92). 
diverses tribunes, com ara a la conferència pronunciada durant el cicle «(Des) aîllats: la insularitat en la narrativa del segle $\mathrm{XX}$ », en què revela que:

Ara sé per què vaig començar [a escriure]. Vaig fer-ho per culpa de l'àvia, incitada per la seva capacitat d'explicar històries, incitada també per les històries que llegia als llibres. Sense aquests antecedents és possible que mai no hagués començat a escriure. (Pons + Sureda 2004: 220)

Fins i tot, com ha observat Gregori (2010: 187), Riera fa referència a l'àvia dins l'univers diegètic de La meitat de l'ànima com a part del joc metaficcional que proposa la novel-la, fent coincidir alguns dels trets de l'àvia Caterina amb els de l'àvia de la protagonista, Lluca, però també deixant-hi entreveure les divergències que permeten al lector àvid no caure en el parany d'identificar-les. En Cap al cel obert, la dedicatòria tampoc no és un paratext menor, ja que la referència a l'àvia reapareix al postfaci i és un element clau per a accentuar l'autoconsciència literària.

El segon aspecte que mereix una atenció més detallada són les dedicatòries de La meitat de l'ànima i Epitelis tendríssims, ja que demostren el funcionament d'aquest paratext com un mecanisme estratègic per a involucrar el lector. En el primer cas, l'ambivalència de l'enunciat «A la meva mare» també està dissenyada per contribuir a la confusió entre realitat i ficció que planteja l'obra (Rodríguez 2010: 119). Si tenim present la quantitat de familiars que figuren en les dedicatòries rierianes, no sembla que en principi aquest missatge haja de generar ambigüitats interpretatives i, d'entrada, és llegit en clau autobiogràfica. Ara bé, a mesura que el lector s'endinsa en la novel-la, troba una història centrada en una figura materna i elaborada a partir de tot un joc d'equívocs que promouen la identificació entre la narradora i l'autora real, moment en el qual posa en qüestió el caràcter real de dedicador i dedicatari. En el cas d'Epitelis tendríssims, la indefinició de la dedicatòria, «A qui ho sap», segueix el to irònic i distanciat de tot el volum, atès que obeeix, com detecta Cotoner (2010: 117), a «una de las premisas fundamentales de la ironía que consiste en decir algo no diciéndolo». L'enigmàtic dedicatari activa en el lector «el mecanismo de morbosa curiosidad propia del erotismo», que li farà especular sobre la identitat d'aquesta figura. Ambdues dedicatòries, per tant, demostren que Riera té ben present en dissenyar aquest paratext la figura del lector-testimoni que Genette reivindica com a dedicatari sempre latent al costat del dedicatari «oficial».

En darrer lloc, cal fer esment específic a la dedicatòria final d'Amb ulls americans perquè cal atribuir-la a l'autor ficcional del text, que és el narrador autodiegètic George MacGregor, i no a Carme Riera, com ja ha apuntat Martínez (2012: 148). En realitat, és una mostra del joc d'ambigüitat continu que planteja l'autora entre realitat i ficció, ja que al pròleg, signat per ella, juga a atorgar-li una existència real al personatge de Sergi, ara dedicatari. La dedicatòria pertany, per tant, al manuscrit de MacGregor i es correspon amb les darreres paraules del llibre: «Per a tu, Sergi, i per la nostra amistat, aquesta sí, hermosa de debò». Aquesta amistat «de debò» és la que manté MacGregor amb Sergi Batllori, molt distinta a l'amistat truncada entre el nord-americà i Albert Puigdevall, qui a l'inici de la novel-la li prometia «una hermosa amistad» 
(Riera 2011: 21, 22). De fet, no és estrany que Sergi siga el dedicatari escollit per MacGregor si tenim en compte que és qui li suggereix escriure aquestes memòries sobre l'estada a Barcelona (Riera 2011: 250) i a qui li remet els seus manuscrits (Riera 2011: 20).

Excepcions al marge, la majoria de dedicatòries del corpus que analitzem responen a un dedicador que s'associa amb l'autora real, Carme Riera, i a uns dedicataris de caràcter privat. Tanmateix, la dada més significativa que cal retenir de tota aquesta anàlisi és la utilització sistemàtica d'un paratext que és facultatiu. Cal notar com Carme Riera aprofita la dedicatòria per a manifestar un reconeixement a les persones que l'envolten, a través del qual ens revela directament $\mathrm{o}$ indirecta les relacions amb el seu entorn més pròxim -fonamentalment amb el cercle familiar-, les condicions que motivaren la gestació de les seues obres o els referents que l'han influenciada. Al costat d'aquests usos, l'escriptora també entén la dedicatòria com una via per a dirigir-se al lector, bé per a condicionar la lectura, bé per a ajudar a interpretar-la, de manera que atorga a aquest paratext un paper no gens secundari en la descodificació del sentit de l'obra.

\section{ELS EPÍGRAFS}

L'epígraf acompleix una funció pragmàtica estratègica en la construcció del sentit global de l'obra: actua sobre les creences i el comportament del lector, estableix hipòtesis de lectura $\mathrm{i}$ en programa possibles interpretacions (Lane 1992: 58). En gran part dels casos és al-lògraf, és a dir, consisteix a citar un text d'altri, factor que permet inscriure l'obra dins d'una tradició estètica o ideològica determinada, ja siga per a ressaltar-ne les afinitats o les divergències. La tendència majoritària a situar-lo a l'inici del llibre i a considerar-lo una instrucció prèvia a la lectura provoca que l'emplaçament terminal atorgue al paratext una significació més contundent o conclusiva.

D'acord amb Genette (1987: 145-149), l'epígraf pot exercir quatre funcions. La primera i la segona actuen com a comentaris interpretatius o justificatius del títol i del text de l'obra respectivament. D'una manera més obliqua, la tercera funció consisteix a ressaltar l'efecte que provoca la identitat de l'epigrafiat, és a dir, el nom de l'autor de la citació, mentre que la quarta funció, batejada amb el terme 'efecte-epígraf', es relaciona amb el joc que suscita la seua simple presència o absència. En aquest sentit, la inclusió d'un epígraf seria un distintiu mitjançant el qual l'autor s'atorga una certa filiació prestigiosa o intellectual.

Carme Riera recorre a l'epígraf en cinc de les setze obres que conformen el corpus d'anàlisi del present estudi: Te deix, amor, la mar com a penyora, Una primavera per a Domenico Guarini, Epitelis tendríssims, Qüestió d'amor propi, i Temps d'innocència. No convé, però, extraure conclusions precipitades d'una dada quantitativa que pot semblar baixa i, en conseqüència, poc determinant. En realitat, analitzem un dels mecanismes paratextuals més rendibles a l'hora de construir un lector model actiu com el que reclama la literatura de Riera. Si, a 
més a més, tenim en compte que tres de les cinc obres esmentades contenen més d'un epígraf, ja no sols ens trobem amb un paratext atractiu d'abordar per si mateix, sinó també per la successió d'ecos que pot produir.

La seua primera obra, Te deix, amor, la mar com a penyora, presenta dos epígrafs inicials i un final:

Jo era a la vegada arbre i ocell, al-lot i al-lota, peix mut dins la mar.

Empèdocles

... (Escolliré per sempre més la teva absència, donzella, perquè el que de veritat estim no és el teu cos, ni el record del teu cos, tan bell sota la lluna; el que de veritat estim és l'empremta que has deixat sobre l'arena)...

Fragment mai no escrit de Safo

Tota la meva vida es lliga a tu, com en la nit les flames a la fosca.

Bartomeu Rosselló-Pòrcel

Els dos primers exerceixen una clara funció de comentari de text, ja que actuen com a pistes temàtiques en alertar del component subversiu i femení del llibre. Sobre la citació inicial del presocràtic Empèdocles, Riera desvelava en una entrevista (Nichols 1989: 211) que la seua intenció era «resumir el artista, es decir, el andrógino. Por eso decía que éramos dos cosas a la vez, y que la naturaleza y el arte son ambiguos por antonomasia». A la llum d'aquestes declaracions, cal relacionar la inclusió de l'epígraf amb una actitud enfrontada a la divisió maniquea de la realitat i cal percebre en les seues paraules una atracció pel tema de l'androgin que evolucionarà cap als motius del doble i l'ambigüitat de les relacions entre identitat $\mathrm{i}$ alteritat en produccions posteriors. Nichols (2011: 22) estudia anys més tard el paratext en relació amb el paradís primigeni del relat bíblic, adduint que aquest espai lliure de motlles, opressions i culpes truncat per la «Llei del Pare» és «el feliç passat que les protagonistes volen rememorar».

El segon epígraf ofereix una clau interpretativa molt més diàfana. La voluntat de Riera de fer present Safo, considerada la primera dona poeta i el referent de la producció literària lèsbica, a la qual presta el nom, és evident. Així, en la mateixa entrevista amb Nichols (1989: 209), Riera confessa que l'interès inicial per la Safo poeta la va conduir «a considerar que la gran aportación de Safo era precisamente elevar a la categoría de objeto del deseo a otra mujer por una mujer, que la mujer fuera a la vez sujeto y objeto del deseo en relación a su propio sexo». En aquest sentit, les connotacions motivades pel nom de l'epigrafiada prefiguren l'efecte sorpresa final del conte que dóna títol al recull. Ara bé, el fet de presentar la citació com un «fragment mai no escrit de Safo» afegeix un punt d'incertesa sobre el seu origen i fa ambigua, doncs, la identitat de l'epigrafiat. En realitat, es tracta d'una atribució d'autoria que fa Riera, una maniobra que li permet destacar una figura simbòlica i representativa d'una tradició literària silenciada durant molts segles, com és l'escrita per dones, i revelar l'actitud decidida a rescatar el protagonisme de les dones. El missatge, que 
també prefigura l'estil poètic i intimista de l'obra, emfasitza la sensació d'absència provocada per la distància que separa les protagonistes de la història. Per a Bettaglio (2008: 70), aquesta absència ompli, paradoxalment, el present: «It is not the body of the beloved, though beautiful, nor its memory, that is valued mostly but l'empremta que has deixat sobre l'arena». Marina, narradora-personatge, evoca l'estimada a través de la creació literària, de la mateixa manera que Safo ho fa amb la «donzella», i a través d'aquest record, transforma l'absència en presència. Ara bé, mentre que la separació de Safo i l'estimada és una decisió conscient, l'aïllament de les amants no és voluntari, sinó causat per un ordre social que castiga i reprimeix l'amor entre dones, tal com Marina declara en la seua carta: «Les nostres relacions [...] foren trencades a causa de l'escàndol públic [...]. T'amenaçaren en nom de la moral i els bons costums, et parlaren de conducta corrompuda [...].» (Riera 1981a: 23)

L'epígraf final reprodueix un emblemàtic vers del poema «A Mallorca, durant la guerra civil», del mallorquí Rosselló-Pòrcel. D'una intensitat aclaparadora, sintetitza magistralment el sentiment d'unió del poeta amb la Mallorca natal que estima, malgrat la dolorosa distància física que els separa. Riera s'hi identifica i l'introdueix com a epígraf final de l'obra per a recalcar la seua identitat insular, una mallorquinitat que condiciona la seua producció literària i la seua visió del món, tal com ella ha expressat en diverses ocasions. Quasi tres dècades més tard inclou el vers a La meitat de l'ànima (Riera 2004: 139), amb idèntic sentit, però inserit en el discurs de la veu narrativa i sense marques tipogràfiques que l'identifiquen com a citació. El personatge de la narradora l'usa per a expressar els profunds lligams que la uneixen al paisatge mallorquí, precisament en uns moments en què s'interroga sobre els seus orígens i, de retop, sobre la seua identitat.

Una primavera per a Domenico Guarini conté dos epígrafs inicials que insinuen algunes de les claus del sentit global de l'obra:

... What mistery here is read of homage or of hope? But how command Dead Springs to answer? And how question here these mummers of that wind-withered New-Year?

Dante Gabriel Rossetti

Hablaré de los viajes del yo a través de sus inevitables máscaras, viajes emocionantes que transforman la personalidad cuando han terminado; los que tienen por fin «la otra orilla», el reino del Preste Juan, la joya dentro del loto, la isla perdida o la princesa lejana; y todos, al terminar, se encuentran donde empezaron. Misteriosos viajes cíclicos cuyo trayecto es el eterno retorno hacia el centro de uno mismo, movidos por el sagrado narcisismo. ¿A dónde vale la pena ir, si no es a sí mismo?

Luis Racionero

El fet que a més de ser reproduïts en la llengua original, anglès i castellà respectivament, compten tot seguit amb la traducció al català pot considerar-se una marca de la voluntat d'assimilar-los, mitjançant l'homogeneïtzació lingüís- 
tica, al diàleg que l'obra estableix amb el lector; a més, de retruc, constitueix un indici simptomàtic de la seua rellevància. Ambdós anticipen el joc simbòlic de seduccions i ambiguiitats a partir del qual se sustentarà la novel-la. Així, els dos fils argumentals -el misteriós atemptat contra el quadre de La primavera i la recerca identitària de la protagonista- actuen en paral-lel a les dues citacions de Dante Gabriel Rossetti i Luis Racionero, que convergeixen en l'afany de descobrir una realitat oculta.

El primer epígraf es correspon a l'última estrofa de «For spring, by Sandro Botticelli», un sonet en què Rossetti demostra la seua fascinació per Botticelli i La primavera encadenant un seguit d'interrogacions que no obtenen resposta. A més de l'al-lusió a les «Primaveres», que cal relacionar amb la pluralitat d'interpretacions que genera el quadre del pintor italià, la citació introdueix també el motiu de la màscara, és a dir, el joc d'aparences enganyoses, seduccions i simulacions a partir del qual es teixirà el discurs narratiu de la novel-la i, més encara, gran part de la producció rieriana posterior ${ }^{5}$.

Segons Tsuchiya (2000: 53), ambdues citacions subratllen «l'absència d'una essència transcendent darrere la força seductora de la màscara», atès que el segon epígraf, de Luis Racionero, torna a insistir en aquesta metàfora de la màscara, a més de subratllar de manera diàfana el tòpic del viatge iniciàtic. Des d'aquest punt de vista, els epígrafs anticipen un dels sentits de la novel-la, vinculat a la il-lusió impossible de fixar una interpretació definitiva del significat artístic i de la identitat personal, ja que la subjectivitat escapa de ser una construcció unívoca i estable. Tot i això, la concepció de l'art i l'individu com a vies epistemològiques (Gregori 1997: 92) possibilita que al final de la història la protagonista accepte la natura «calidoscòpica» de la pròpia imatge, anàloga a la multiplicitat de significats al-legòrics que amaga el quadre de Botticelli:

Tremola la teva pròpia imatge -totes les versions de tu mateixa, totes les possibilitats del teu ésser, totes les màscares-, desapareix, es recompon, calidoscòpica, al fons d'aquest mirall anomenat La primavera. (Riera 1981b: 180)

Si seguim la teoria genettiana, no hi ha dubte que les dues citacions liminars d'Una primavera per a Domenico Guarini són una mostra òptima de la funció de comentari de text que poden exercir els epígrafs. I encara podem adduir l'existència d'una clau temàtica més, proporcionada pel nom de l'epigrafiat, Dante Gabriel Rossetti, que és possible relacionar amb el personatge Domenico Guarini, tal com suggereix Machein (2009: 167). El prerafaelita Rossetti i Guarini comparteixen un ideal de feminitat, el de la «donna angelicata», influenciat pel petrarquisme i el neoplatonisme. L'amor obsessiu de Guarini per Laura -nom

5 Passades més de tres dècades des de la publicació de la novel·la, Riera (2016) ha tornat recentment a relacionar el quadre de Botticelli amb el vers de Rossetti en un dels articles que publica quinzenalment a La Vanguàrdia: «Des del meu punt de vist, és Dante Gabriel Rossetti, que amb tanta devoció va estudiar la pintura del florentí i es va preguntar en un bell poema sobre el misteri d'homenatge o esperança que impregna l'Al-legoria de la primavera, qui capta millor l'enigma de Botticelli, esotèric, gran mestre de la Confraria de Sió, estrany i genial». 
de clares reminiscències petrarquistes- representa la idealització de la figura femenina i l'essència amorosa que exaltaven de la mateixa manera els prerafaelites.

En Epitelis tendríssims, obra que inicia el nou tombant de la producció rieriana cap al distanciament irònic, el recurs a l'epígraf arriba al punt àlgid en l'ús que en fa l'autora. El recull conté tres epígrafs inicials que, tant pel seu contingut com per la identitat dels epigrafiats, palesen la voluntat de transgredir el model tradicional de sexualitat: Vaig adonar-me que la caixa de Pandora guardava els misteris de la sexualitat
femenina, tan distinta de la masculina, i que el llenguatge dels homes no era
adequat per a descriure-la. El llenguatge del sexe encara s'ha d'inventar. El
llenguatge dels sentits ha d'explorar-se.

Anaïs Nin

Jehovà destrueix la ciutat a causa del pecat de Sodoma i el resultat és el pecat de l'incest. Quina lliçó contra els decrets de la Justícia! I, ambdós pecats, quina manifestació del poder del sexe!

Federico García Lorca

El plaer és el millor dels compliments.

Coco Chanel

El primer i el tercer són citacions de dues dones avançades al seu temps, Anaïs Nin i Coco Chanel, esdevingudes icones col-lectives de l'alliberament de la dona en haver revolucionat la identitat femenina. La inclusió del fragment de Nin s'ha d'entendre com un homenatge a una de les primeres dones que va publicar literatura eròtica i que Riera agafa com a referent per a acostar-se al gènere. Malgrat el to irònic adoptat, l'epígraf representa també un propòsit «seriós» del llibre: endinsar-se en l'autoconeixement des d'una òptica nítidament femenina i desacomplexada i contribuir, així, a construir aquest llenguatge que encara «s'ha d'explorar». En aquesta mateixa línia l'interpreta Cotoner (2010: 118), que considera «la exploración del lenguaje del sexo» un dels eixos temàtics fonamentals del llibre, així com també relaciona la citació de Coco Chanel amb una altra línia temàtica, en aquest cas, «la incitación al placer». Com és sabut, Chanel va alliberar l'armari femení de la rigidesa i el va conduir cap a la comoditat i l'elegància, un aspecte que lliga amb el to desenfadat $\mathrm{i}$ lúdic des del qual Riera planteja la visió de l'erotisme.

L'epígraf de Federico García-Lorca, que apareix intercalat entre els anteriors, és un comentari literal del poeta andalús a l'argument de la seua obra dramàtica La destrucción de Sodoma, que no va arribar a completar i de la qual només se n'han conservat uns pocs fragments inicials (Martínez 2004: 265). S'hi al-ludeix al conegut i tràgic episodi bíblic que tradicionalment ha servit per a condemnar els «pecats» de l'homosexualitat i de l'incest i, en definitiva, qualsevol afany de llibertat i subversió sexual. L'epígraf pot llegir-se, doncs, com una invitació a capgirar aquesta lectura canònica, en considerar els pecats una 
«manifestació del poder del sexe!». Segons el parer de Cotoner (2010: 118), la inclusió d'aquest epígraf resulta incoherent amb la línia eròtica i irònica traçada per les citacions de Nin i Chanel, raó que pot explicar per què l'autora l'elimina en la versió en castellà de l'obra, publicada a El hotel de los cuentos y otros relatos de neuròticos (Alfaguara 2008), i el substitueix per un altre de Cristina de Suècia: «La vida sin humor sería insoportable». A més d'homogeneïtzar tot l'espai paratextual de l'epígraf amb veus femenines, la citació encaixa amb el to irònic del llibre i amb un dels eixos temàtics, com és «la necesidad del humor para combatir la usura incansable del tiempo.» (Cotoner 2010: 118).

Qüestió d'amor propi presenta un epígraf de Jaime Gil de Biedma, un poeta en què Carme Riera s'ha especialitzat des del seu vessant de catedràtica i professora de literatura espanyola. Es correspon als darreres versos del poema «Contra Jaime Gil de Biedma»: « Oh innoble servidumbre de amar seres humanos, y la más innoble que es amarse a sí mismo!». Durant tota la composició, el jo empra una ironia distanciadora per a discutir amb la seua consciència, escindint-se així en dos punts de vista contradictoris, fins que acaba assumint el seu narcisisme. Àngela, la protagonista de la novel-la, també es troba sotmesa al seu amor propi en idear una venjança contra l'antic amant de la qual s'enorgulleix. El seu ressentiment és una de les conseqüències provocades per un amor inevitable, que no es pot decidir ni controlar, com és l'amor a si mateix. Des d'aquesta perspectiva, que encaixa amb la funció de comentari de text de l'epígraf teoritzada per Genette, ben bé es pot interpretar ja no sols aquest paratext, sinó tota l'obra, en la línia d'aquell aforisme amb el qual Joan Fuster ja advertia: «Moltes ferides d'amor són només ferides d'amor propi.» (2003: 39).

En darrer lloc, Temps d'innocència conté un epígraf que acompleix de manera canònica tant la funció de comentari de text com la de l'efecte provocat per la identitat del seu autor. La citació és un fragment del poema «Ara», de Clementina Arderiu:
Ara que ja de tanta cosa torno
No em pregunteu, que no sabria dir-vos
per quina brida m'he sentit lligada.
El cor encara vol tornar a gronxar-se
desbocat a les barques de la fira;
i dic que sí, que en mi tot clama d'esma
cap aquella petita esbojarrada.

Temàticament, no hi ha dubte que tant Arderiu com Riera coincideixen a rememorar l'univers infantil des d'una òptica ja madura. Els versos d'Arderiu poden ser considerats un pretext a partir del qual Riera comença les seues memòries d'infantesa. També, la identitat de l'epigrafiada demostra el seu interès per rescatar i reconèixer la tradició literària femenina. De fet, a causa d'aquesta voluntat de donar visibilitat a les dones dins del cànon literari, l'escriptora 
mallorquina ha publicat l'Antologia de la poesia catalana femenina (2003), que recull produccions de quinze poetes catalanes del segle XX, entre les quals figura Clementina Arderiu.

Si bé Genette adverteix que aquest paratext pot generar tantes interpretacions com lectors pot tenir, és precisament aquest tret de defugir lectures unidireccionals el que el fa atractiu. Les pàgines anteriors ens han permès, almenys, observar tres tendències interessants relatives a l'ús de l'epígraf en la narrativa de Riera que, a tall de recapitulació, convé ara remarcar. En primer lloc, l'epígraf rierià, al-lògraf i preliminar, revela una clara intenció d'anunciar claus temàtiques del text a què acompanya. Al marge queda el vers de Rosselló-Pòrcel, situat al final de Te deix, amor, la mar com a penyora, que cal relacionar més aviat amb la figura de l'autora que no amb l'argument de la història. En segon lloc, convé tenir present la funció d'efecte-epígraf que proposa Genette perquè Riera, mitjançant aquest paratext, insereix en el seu discurs un seguit de referents clàssics i contemporanis. D'aquesta manera, demostra posseir un ampli bagatge cultural que, certament, també exhibeix amb la densa xarxa d'intertextualitats que travessen les seues obres. En tercer lloc, Riera perfila des de l'epígraf la postura ideològica i moral compromesa amb la dona en citar algunes de les seues referents femenines i en col-locar, així, la seua obra dins d'una tradició que vol homenatjar. Fet i fet, tres tendències que permeten considerar l'epígraf com un paratext significatiu per a acostar-se a l'univers literari de l'escriptora mallorquina.

\section{CONCLUSIONS}

L'anàlisi dels títols, les dedicatòries i els epígrafs de Carme Riera ens ha permès aproximar-nos a conèixer el paper que ocupa la paratextualitat en la seua narrativa. Si bé assumim que no és ni de bon tros exhaustiu, aquest estudi ens ha possibilitat detectar algunes tendències generals relatives al seu ús, com ara el predomini incontestable dels títols temàtics, amb una lleugera superioritat de l'element metafòric, l'ús sistemàtic de les dedicatòries malgrat ser un paratext facultatiu i la concepció de l'epígraf com un mecanisme essencial per a anunciar claus temàtiques de l'obra i fixar l'univers de referències culturals explícites entre el text i altres textos. A més a més, el recorregut traçat per aquestes tres categories paratextuals ens ha permès advertir els jocs que sovint estableixen entre elles, bé al si d'una mateixa obra, bé a l'hora d'entrellaçar obres diferents. Tanmateix, si hi ha un tret que confereix atractiu a l'estudi del paratext rierià és, sens dubte, la capacitat decisòria que li atribueix l'autora, ja no sols perquè aporta pistes per a copsar el sentit del conjunt del text, sinó també perquè a través d'ell és possible reconèixer diferents etapes productives o delimitar alguns dels nuclis temàtics al voltant dels quals es vertebra la literatura rieriana. En aquest sentit, tot i que no és l'objectiu del present treball, l'anàlisi dels paratextos originals, contrastada amb els de les traduccions a altres llengües, permetria traure'n conclusions de gran interès, sobretot en les versions en castellà, obra de la mateixa Riera. A tall de mostra, podem observar les 
divergències entre el títol original Joc de miralls i el de la traducció castellana del mateix any, Por persona interpuesta.

Amb tot, no seria agosarat afirmar que, si bé el paratext és un discurs que no pot desvincular-se del seu text, Carme Riera confegeix textos que en moltes ocasions no poden desvincular-se del seu paratext. L'estudi que hem portat a terme, més que abocar-se a un objecte perfilat i autosuficient, se'ns ha revelat com un mitjà idoni per a explorar el joc literari global que proposa l'escriptora. $\mathrm{Cal}$ entendre, doncs, el funcionament de la paratextualitat en la narrativa rieriana no sols com un vestíbul que possibilita l'accés al text, sinó com una gran via de comprensió del seu univers literari.

\section{BIBLIOGRAFIA}

\section{Obres de Carme Riera citades}

Riera, C. (1981a) Te deix, amor, la mar com a penyora, Barcelona, Laia.

- (1981b) Una primavera per a Domenico Guarini, Barcelona, Edicions 62.

- (1987a) Epitelis tendríssims, Barcelona, Edicions 62.

- (1987b) Qüestió d'amor propi, Barcelona, Laia.

- (1991) Contra l'amor en companyia i altres relats, Barcelona, Destino.

- (1996) Joc de miralls, Barcelona, Planeta.

- (1998a) Jo pos per testimoni les gavines, Barcelona, Columna.

- (1998b) Temps d'una espera, Barcelona, Columna.

- (2004) La meitat de l'ànima, Barcelona, Cercle de Lectors.

- (2006) L'estiu de l'anglès, Barcelona, Proa.

- (2011) Amb ulls americans, Barcelona, LaButxaca.

- (2013) Dins el darrer blau, Barcelona, LaButxaca.

- (2014a) Cap al cel obert, Barcelona, LaButxaca.

- (2014b) Temps d'innocència, Barcelona, LaButxaca.

- (2015a) La veu de la sirena, Barcelona, Edicions 62.

- (2015b) Natura quasi morta, Barcelona, LaButxaca.

\section{Referències}

Ardolino, F. (2000) «La ficció epistolar de Carme Riera», Journal of Catalan Studies, 3, <http://www.uoc.edu/jocs/3/articles/ardolino4/>. [Consulta: 3 novembre 2015].

- (2006) «Ou sont les vierges d'antan? Carme Riera contista», Caràcters, 34, pp. 28-29. 
Arnau, P. + Cotoner, L. (eds.) (2011) Els subjectes de l'alteritat: estudis sobre la narrativa de Carme Riera, Barcelona, Publicacions de l'Abadia de Montserrat.

Bartrina, F. (2011) «Narratives de la identitat a Cap al cel obert, de Carme Riera», Els subjectes de l'alteritat: estudis sobre la narrativa de Carme Riera, P. Arnau i L. Cotoner (eds.), Barcelona, Publicacions de l'Abadia de Montserrat, pp. 59-74.

Bettaglio, M. (2008) Gestating a text, delivering a mother: Maternal and textual bodies in Carme Riera and Lucía Etxebarría, Tesi doctoral, Buffalo, State University of New York.

Corrons, F. + Frayssinhes-Ribes, S. (eds.) (2010) Lire Carme Riera. À propos de «La meitat de l'ànima», Péronnas, Editions de la Tour Gile.

Cotoner, L. (1996) «Marco escénico e interpretación simbólica de los espacios en Dins el darrer blau de Carme Riera», Lectora: revista de dones i textualitat, 2, pp. 33-41.

- (2010) «Ironía y autotraducción: de Epitelis tendríssims a El hotel de los cuentos», Quaderns. Revista de traducció, 17, pp. 115-129.

Durán, L. (2009) «He escrito una novela irónica que pone de manifiesto el ombliguismo catalán», Diario de Mallorca (26-5-2009).

Epps, B. (2011) «Amb els ulls de Carme Riera: Entre la ingenuïtat típica i la llibertat atípica», Els subjectes de l'alteritat: estudis sobre la narrativa de Carme Riera, P. Arnau i L. Cotoner (eds.), Barcelona, Publicacions de l'Abadia de Montserrat, pp. 119-143.

Fuster, J. (2003) Judicis finals, València, Publicacions de la Universitat de València / Càtedra Joan Fuster [1a ed., 1960, Palma de Mallorca, Ed. Moll].

Genette, G. (1987) Seuils, París, Éditions du Seuil.

Gregori, C. (1997) «Identitat i alteritat en les novel-les de Carme Riera», Caplletra, 22, pp. 91-103.

- (2010) «Pacte metaficcional i identitat literària, una proposta per al lector model a La meitat de l'ànima», Lire Carme Riera. À propos de «La meitat de l'ànima», F. Corrons i S. Frayssinhes-Ribes (eds.), Péronnas, Editions de la Tour Gile, pp. 181-200.

- (2011) «El títol com a clàusula del contracte metaficcional irònic en la narrativa contemporània», La literatura davant el mirall. Ironia i metaliteratura en l'època contemporània, F. Carbó, C. Gregori, G. López-Pampló, R. Rosselló i V. Simbor (eds.), Barcelona, Publicacions de l'Abadia de Montserrat, pp. 47-84.

- (2013) «Imatges del món i miralls literaris. L'escriptura metaficcional en l'obra de Carme Riera», Lectora: revista de dones i textualitat, 19, pp. 13-23.

Julià, L. (2009) Carme Riera, Barcelona, AELC. 
Lane, P. (1992) La periphérie du texte, Paris, Nathan.

Machein, S. (2009) Topologien der Geschlechter. Die Revision traditioneller Raumordnungen im Postfranquismus am Beispiel von Esther Tusquets, Carme Riera und Clara Janés, Tesis doctoral, Heidelberg, Ruprecht-Karls-Universität, Heidelberg.

Martínez, A. (2004) «Personajes femeninos de la obra de Federico García Lorca», Pasajes = Passages = Passagen: homenaje a Christian Wentzlaff-Eggebert, V. Heinen, S. Grunwald, C. Hammerschmidt i G. Nilsson (eds.), Sevilla, Universidad de Sevilla-Secretariado de Publicaciones, pp. 251-268.

Martínez, H. (2012) «Con ojos americanos y el cañamazo del Lazarillo (Un ejemplo de intertextualidad creativa)», Tejuelo, 13, pp. 142-160.

Nichols, G. (1989) «Carme Riera», Escribir, espacio propio: Laforet, Matute, Moix, Tusquets, Riera y Roig por sí mismas, Minneapolis, Institute for the Study of Ideologies and Literature, pp. 187-227.

- (2011) «La memòria de l'ordre de les coses a l'obra de Carme Riera», Els subjectes de l'alteritat: estudis sobre la narrativa de Carme Riera, P. Arnau i L. Julià (eds.), Barcelona, Publicacions de l'Abadia de Montserrat, pp. 15-32.

Pons, M. + Sureda, C. (eds.) (2004) (Des)aïllats: Narrativa contemporània $i$ insularitat a les Illes Balears, Barcelona, Publicacions de l'Abadia de Montserrat.

Ramon, A. (2013) «Pintar com escriure. Una passejada pels museus rierians», Lectora: revista de dones i textualitat, 19, pp. 65-80.

Riera, C. (2016) «A Londres, amb Botticelli», La Vanguàrdia (13-3-2016).

Rodríguez, M. P. (2010) «La seducción de la madre en La meitat de l'ànima», Lire Carme Riera. À propos de «La meitat de l'ànima», F. Corrons i S. Frayssinhes-Ribes (eds.), Péronnas, Editions de la Tour Gile, pp. 117-133.

Televisió de Catalunya + Undatia Comunicació (2014) (S)avis: Carme Riera, Barcelona, Televisió de Catalunya. <http://www.ccma.cat/tv3/alacarta/savis/ carme-riera/video/5388851/>. [Consulta: 26 març 2016].

Tsuchiya, A. (2000) «Seducció i simulació a Una primavera per a Domenico Guarini de Carme Riera», El mirall i la màscara, L. Cotoner (ed.), Barcelona, Destino, pp. 51-72.

Valls, F. (2000) «Primera lectura de Cap al cel obert», El mirall i la màscara, L. Cotoner (ed.), Barcelona, Destino, pp. 301-314. 